DOI: http://dx.doi.org/10.25181/jofsa.v2i1.759

Journal of Food System and Agribusiness Vol. 2 (1): 35-54

\title{
STRATEGI PEMASARAN AYAM PROBIO (broiler) PADA KELOMPOK PETERNAK AYAM (KPA) BERKAT USAHA BERSAMA (BUB) KOTA METRO
}

\author{
MARKETING STRATEGY OF PROBIO (broiler) CHICKEN ON CHICKEN LIVESTOCK GROUP \\ (KPA) BERKAT USAHA BERSAMA (BUB) METRO CITY
}

\section{Nyoman Sulindre, Djoko Umar Said, Zulkarnain ${ }^{1}$}

${ }^{1}$ Sekolah Tinggi Ilmu Pertanian (STIPER) Dharma Wacana, Kota Metro, Indonesia

${ }^{1}$ E-mail : zulfadhilalzabir@gmail.com

\begin{abstract}
The cultivation and processing of chicken probio (broiler) in LampungProvince was initiated by Kelompok Peternak Ayam (KPA) Berkat Usaha Bersama (BUB) in Metro City. KPA BUB was established on March 22, 2008 with members of 30 farmers. KPA BUB acts as a facilitator for its members. This study aims to analyze the Probio Chicken Marketing Strategy (Broiler) in Kelompok Peternak Ayam (KPA) Berkat Usaha Bersama (BUB) Metro City. The problem to be analyzed is how the marketing strategy is implemented by Chicken Breeder Group (KPA) Berkat Usaha Bersama (BUB) Metro City. The method used in this research was non probability sampling, that is snowball sampling technique with population of 30 probio chicken breeders. The number of sample were 25 respondents consisting of 20 farmers and 5 practitioners. Analysis tool used in this research was a descriptive analysis using SWOT analysis technique. Primary and secondary data were used. The results of this study showed that the SWOT matrix obtained coordinates $(0.32,0.37)$, i.e. the Strengh-Opporturnities (SO) strategy, in which the coordinates were entered in Quadrant I. Strategies that can be used are 1) Developing probio chicken products and good service to consumers by seeing the growing market growth would increase the number of probio chicken production; 2) Good service to consumers, the quality of products, and the sales cycle increased with the increasing pattern of consumer behavior that would develop the needs of the society of probio chicken consumption, 3) The strength of business and good management by utilizing a strategic plant location for promotion / advertising would increase the amount of production so the community needs for chicken probio can be met.
\end{abstract}

Nyoman Dkk (Strategi Pemasaran Ayam Probio (Broiler) Pada Kelompok Peternak Ayam (Kpa) Berkat Usaha Bersama (Bub) Kota Metro) 
DOI: http://dx.doi.org/10.25181/jofsa.v2i1.759

Journal of Food System and Agribusiness Vol. 2 (1): 35-54

Keywords: marketing strategy, probio chicken (broiler).

Disubmit :30 April 2018 Diterima:30 Maret 2018, Disetujui :1 April 2018

\section{PENDAHULUAN}

Agribisnis berbasis peternakan adalah salah satu fenomena yang tumbuh pesat ketika ketersediaan lahan menjadi terbatas, karena sistem usahatani memerlukan lahan yang besar namun ketersediaan lahan yang terbatas akan memicu efisiensi dan efektifitas penggunaan lahan tersebut. Oleh karena itu usaha peternakan dapat dijadikan salah satu alternatif yang menjanjikan nilai keuntungan dimasa depan (Arifin, 2004).

Usaha peternakan di Indonesia terdiri atas ternak sapi potong, sapi perah, kerbau, kuda, kambing, domba, babi, ayam buras, ayam ras petelur,pemasok ayam ras pedaging, kondisi ini mendorong para peternak untuk menambah populasi guna meningkatkan produksi ayam ras pedaging.Kota Metro sebagai salah satu sentra usaha peternakan unggas memiliki populasi ayam ras pedaging tertinggi yaitu 1.183.200 ekor ditahun 2016, dibandingkan populasi ayam buras, ayam petelur, dan itik (Badan Pusat Statistik Lampung, 2017).Berdirinya usaha ternak ayam ras pedaging (broiler) probio, Kota Metro merupakan kota perintis pertama di Provinsi Lampung. Ayam broiler probiotikatau ayam probio adalah ayam broiler yang dipelihara secara organik, yaitu dengan menggunakan probiotik dan herbal jamu sebagai tambahan pakan dan antibiotik.Sehingga tidak terdapat residu bahan kimia dalam tubuh ayam tersebut, dan menghasilkan daging ayam yang sehat dan berkualitas organik sehingga aman dikonsumsi dan baik bagi kesehatan. (Direktur jendral Pengolahan dan Pemasaran Hasil Pertanian, 2014).

Peluang bisnis ayam broiler organik semakin meningkat seiring dengan meningkatnya kesadaran masyarakat terhadap pola hidup sehat.Sebagaimana diketahui, kecenderungan pangan organik dalam negeri secara umum direspon positif, mulai dari beras organik, sayuran organik, hingga broiler organik (Jayanata dan Harianto, 2011).Peluang bisnis usaha ternak ayam broiler organik (probio) sangat besar karena peternak dapat memasarkan produknya tanpa harus bersaing dengan peternak broiler biasa sebab sasaran pasarnya berbeda namun seiring berjalannya waktu cukup banyak perusahaan yang mulai membudidayakan ayam probio.

Pembudidayaan dan pengolahan ayam probio di Provinsi Lampung menurut Direktorat Jendral Pengolahan dan Pemasaran Hasil Pertanian (2014) diprakarsai oleh Kelompok Peternak Ayam (KPA) Berkat Usaha Bersama (BUB) di Kota Metro. KPA BUB berdiri sejak tanggal 22 Maret 2008 dengan jumlah

Nyoman Dkk (Strategi Pemasaran Ayam Probio (Broiler) Pada Kelompok Peternak Ayam (Kpa) Berkat Usaha Bersama (Bub) Kota Metro) 
DOI: http://dx.doi.org/10.25181/jofsa.v2i1.759

Journal of Food System and Agribusiness Vol. 2 (1): 35-54

anggota peternak sebanyak 30 orang.KPA BUB berperan sebagai fasilitator bagi anggotanya, yakni yang menyediakan faktor produksi, rumah pemotongan ayam dan pasar bagi anggotanya. KPA BUB memiliki distributor besar di Jakarta yang bernama Natura Pangan sehingga wilayah pemasaran ayam probio KPA BUB dapat menembus pasar interlokal, bahkan pasarterbesar ayam probio KPA BUB berada di pasar interlokal yakni Jakarta, Jawa dan Bali (Natura Pangan). Jumlah penjualan daging karkas ayam probio KPA BUB dapat dilihat pada Tabel 1.

Tabel 1.Penjualan Daging Karkas Ayam Probio KPA BUB Kota Metro Tahun 2012-2016

\begin{tabular}{llccccc}
\hline \multirow{2}{*}{ No } & \multirow{2}{*}{ Regional } & \multicolumn{5}{c}{ Jumlah Penjualan (ekor/tahun) } \\
\cline { 2 - 7 } & 2012 & 2013 & 2014 & 2015 & 2016 \\
\hline 1. & Jakarta & 70.000 & 107.000 & 123.000 & 142.000 & 163.000 \\
2. & Bali & - & - & - & 3.000 & 3.500 \\
3. & Bandung & - & - & 6.000 & 6.900 & 7.950 \\
4. & Bekasi & - & - & - & 5.000 & 5.750 \\
5. & Metro & - & 16.800 & 19.300 & 22.200 & 25.550 \\
6. & Tambun & - & - & - & 1.500 & 1.750 \\
7. & Bandar & - & 9.600 & 11.000 & 12.650 & 14.600 \\
& lampung & - & & & \\
\hline & Total & $\mathbf{7 0 . 0 0 0}$ & $\mathbf{1 3 3 . 4 0 0}$ & $\mathbf{1 5 9 . 3 0 0}$ & $\mathbf{1 9 3 . 2 5 0}$ & $\mathbf{2 2 2 . 1 0 0}$ \\
\hline
\end{tabular}

Sumber : Profil KPA Berkat Usaha Bersama, 2016.

Berdasarkan Tabel 1dapat diketahui bahwa jumlah penjualan daging karkas ayam probio KPA BUB selalu mengalami peningkatan per tahunnya dengan wilayah pemasaran terbesar berada di Kota Jakarta, dikarenakan pola prilaku konsumen yang semakin berkembang dan lebih peduli terhadap kualitas bukan kuantitas (Maporina, 2005 dalam Airine, 2010).

Tidaklah gampang untuk mempertahankan suatu perusahaan dengan jenis Secondary Product (kebutuhan tambahan) yang tidak selalu dibutuhkan masyarakat apalagi produk tersebut dijual dengan harga cukup tinggi, dimana satu ekor Ayam Probio dijual dengan harga sekitar Rp.35.000,00. Apalagi saat ini dimana situasi perekonomian sedang sulit dan didalam memasarkan produknya KPA BUBharus bersaing dengan perusahaan-perusahaan sejenis seperti Natura dan Radio Farm, serta minimnya pengetahuan masyarakat tentang Ayam Probio.

Oleh sebab itu, KPA BUB memerlukan strategi pemasaran yang tepat dan harus terus dijalankan agar apa yang telah diraihnya dapat terus bertahan serta semakin menuju kearah peningkatan, baik dari segi penjualan maupun citra perusahaan dan pengembangan dalam mengeluarkan produk baru. Strategi yang Nyoman Dkk (Strategi Pemasaran Ayam Probio (Broiler) Pada Kelompok Peternak Ayam (Kpa) Berkat Usaha Bersama (Bub) Kota Metro) 
DOI: http://dx.doi.org/10.25181/jofsa.v2i1.759

Journal of Food System and Agribusiness Vol. 2 (1): 35-54

dapat dilakukan dalam pemasaran tiwul instan di Desa Wonosari Kecamatan Pekalongan Kabupaten Lampung Timur berdasarkan hasil analisis yang disajikan pada matrik SWOT (Zulkarnain, 2017). Pemanfaatan strategi pemasaran diperlukan untuk mempublikasikan, menyebarluaskan informasi dan memberikan pemahaman serta mendapatkan hasil yang sempurna, positif dan berjalan dengan baik, sehingga KPA BUB akan tetap menjadi pelopor produsen Ayam Probio, dan semakin dikenal oleh masyarakat luas agar tetap menjadi pilihan utama bagi para konsumen sehingga mereka semua tidak akan berpindah ke produk pesaing atau pun ke produk sejenis lainnya.

\section{METODELOGI PENELITIAN}

Tempat dan Waktu Penelitian. Penelitian akan dilaksanakan di Kelompok Peternak Ayam (KPA) Berkat Usaha Bersama (BUB) Kota Metro. Lokasidipilih secara sengaja dengan alasan KPA BUB merupakan perintis pertama dan satu-satunya kelompok yang menghasilkan ayam probio di Provinsi Lampung. Waktu penelitian dilaksanakan pada bulan September - bulan Desember 2017.

Metode Pengumpulan Data. Metode pengumpulan data berupa suatu pernyataan tentang sifat, keadaan, kegiatan tertentu dan sejenisnya.Pengumpulan data dilakukan untuk mendapatkan suatu informasi yang dibutuhkan dalam mencapai tujuan penelitian.Pengumpulan data dalam penelitian ini dilakukan dengan beberapa metode sebagai berikut : 1. Observasi, Observasi adalah teknik pengumpulan data yang dilakukan dengan cara mempelajari dan mengadakan pengamatan secara langsung kedalam perusahaan untuk mendapatkan bukti-bukti yang dapat mendukung dan melengkapi hasil penelitian. 2. Wawancara, Wawancara adalah teknik pengumpulan data berupa sebuah tanyajawab yang dapat dilakukan secara langsung antar penulis dan pihak yang berhubungan dengan objek yang sedang ditelitidengan dibantu daftar pertanyaan (kuesioner) dimana hal ini dimaksudkan untuk mendapatkan data yang akurat dan teliti. 3 . Studi Pustaka (Library Research) yaitu teknik pengumpulan data dari berbagai bahan pustaka (Referensi) yang relevan dan mempelajari yang berkaitan dengan masalah yang akan dibahas.

Jenis Dan Sumber Data. Data yang dipakai dalam penelitian ini adalah data primer dan data sekunder. Data primer yaitu data yang diperoleh langsung dari responden dengan cara observasi, wawancara sesuai dengan keadaan yang sebenarnya. Data sekunder yaitu data yang diperoleh dalam bentuk yang sudah diolah mengenai gambaran umum perusahaan, buku-buku, artikel-artikel dan beberapa literatur yang relevan.

Nyoman Dkk (Strategi Pemasaran Ayam Probio (Broiler) Pada Kelompok Peternak Ayam (Kpa) Berkat Usaha Bersama (Bub) Kota Metro) 
DOI: http://dx.doi.org/10.25181/jofsa.v2i1.759

Journal of Food System and Agribusiness Vol. 2 (1): 35-54

Populasi dan Sampel. Metode pengumpulan data yang terkait dengan populasi adalah para peternak ayam probio Kelompok Peternakan Ayam (KPA) Berkat Usaha Bersama (BUB)Kota Metro yang berprofesi sebagai peternak ayam probio yang berjumlah 30 peternak. Sedangkan jumlah sampel penelitian KPA BUBadalah sebanyak 25 responden yang terdiri dari 20 orang peternak ayam probio dan 5 para praktisi seperti ketua kelompok, 2 orang dinas peternakan Kota Metro dan 2 orang konsumen. Pengambilan sampel diambil dengan caranon probability samplingyakni teknik snowball sampling (Sugiyono, 2009). Namun, apabila peneliti belum mendapatkan data yang cukup, maka peneliti dapat mencari sampel lain sampai mendapatkan data yang cukup.

Analisis SWOT. Analisis data yang digunakan adalah Analisis SWOT, yakni metode untuk indentifikasi berbagai faktor secara sistematis untuk merumuskan strategi yang diperlukan. Analisis didasarkan pada logika yang dapat memaksimalkan kekuatan (strengths) dan peluang (opportunities), namun secara bersamaan dapat meminimalkan kelemahan (weaknesses) dan ancaman (threats) (Rangkuti, 2010). Dalam melakukan identifikasi pemasaran Ayam Probio, dari data yang diperoleh melalui survey di lapangan.Analisis SWOT dilakukan untuk mendapatkan alternatif-alternatif strategi pemasaran ayam probio di KPA BUB.Alat yang dipakai untuk menyusun faktor-faktor strategis adalah matrik SWOT.Matrik ini dapat menggambarkan secara jelas peluang dan ancaman eksternal yang dihadapi dapat disesuaikan dengan kekuatan dan kelemahan yang dimiliki dapat dilihat pada gambar 1 .

MATRIKS SWOT

\begin{tabular}{|c|c|c|}
\hline EFAS & $\begin{array}{l}\text { STRENGTHS (S) } \\
\text { Tentukan 5-10 faktor- } \\
\text { faktor kekuatan } \\
\text { internal }\end{array}$ & $\begin{array}{l}\text { WEAKNESSES (W) } \\
\text { Tentukan 5-10 faktor- } \\
\text { faktor kelemahan internal }\end{array}$ \\
\hline $\begin{array}{l}\text { OPPORTUNITIES } \\
\text { (O) } \\
\text { Tentukan 5-10 faktor } \\
\text { peluang eksternal }\end{array}$ & $\begin{array}{l}\text { STRATEGI SO } \\
\text { Ciptakan strategi yang } \\
\text { menggunakan } \\
\text { kekuatan untuk } \\
\text { memanfaatkan } \\
\text { peluang }\end{array}$ & $\begin{array}{l}\text { STRATEGI WO } \\
\text { Ciptakan strategi yang } \\
\text { menggunakan kekuatan } \\
\text { untuk meminimalkan } \\
\text { kelemahan untuk meraih } \\
\text { peluang }\end{array}$ \\
\hline
\end{tabular}

Nyoman Dkk (Strategi Pemasaran Ayam Probio (Broiler) Pada Kelompok Peternak Ayam (Kpa) Berkat Usaha Bersama (Bub) Kota Metro) 
DOI: http://dx.doi.org/10.25181/jofsa.v2i1.759

Journal of Food System and Agribusiness Vol. 2 (1): $35-54$

\begin{tabular}{|l|l|l|}
\hline TREATHS (T) & STRATEGI ST & STRATEGI WT \\
Tentukan 5-10 faktor & Ciptakan strategi yang & Ciptakan strategi yang \\
ancaman eksternal & menggunakan & meminimalkan kelemahan \\
& $\begin{array}{l}\text { kekuatan untuk } \\
\text { mengatasi ancaman }\end{array}$ & $\begin{array}{l}\text { untuk menghindari } \\
\text { ancaman }\end{array}$ \\
\hline
\end{tabular}

Gambar 1. Analisa SWOT

Sumber : Rangkuti, 2010.

\section{HASIL PENELITIAN DAN PEMBAHASAN}

\section{Gambaran Umum Kelompok}

Latar Belakang Kelompok. Melihat kenyataan bahwa jumlah lapangan kerja yang sangat terbatas khususnya di wilayah Kota Metro Propinsi Lampung yang menyebabkan semakin meningkatnya jumlah pengangguran karena sulitnya mendapatkan pekerjaan, dimana kenyataannya masih banyak lahan yang bisa diolah dan dimanfaatkan, sementara ketidaktahuan akan jenis usaha yang bisa dikembangkan serta ketiadaan modal untuk memulainya, Kelompok Peternak Ayam (KPA) Berkat Usaha Bersama (BUB) lahir dan berdiri dengan maksud membantu mengembangkan dan memanfaatkan potensi yang ada baik lahan maupun tenaga kerja manusianya dengan memberikan pengetahuan ketrampilan beternak Ayam Probio / Ayam Herbal dari awal sampai proses akhir dengan harapan masyarakat yang tidak sempat memperoleh pekerjaan mampu mandiri dengan menciptakan lapangan kerja sendiri dan mendapatkan penghasilan dengan memanfaatkan potensi yang ada sehingga akan meningkatkan kualitas hidup mereka.

Latar Belakang Produk. Daging ayam merupakan komoditi pangan hewani yang sangat diminati masyarakat karena harganya relatif terjangkau, serta ketersediaan yang kontinyu mencukupi dan mudah diperoleh dimanamana.Tingginya permintaan daging ayam tersebut sekaligus merupakan peluang yang memacu minat pelaku usaha kecil di sektor hilir ikut berperan dalam usaha ini, disamping kesadaran hidup masyarakat untuk mulai menjalani pola hidup sehat dengan mengkonsumsi makanan sehat.Karena hal tersebut, Kelompok Perternak Ayam (KPA) Berkat Usaha Bersama (BUB) mencoba untuk melakukan upaya dengan memproduksi ayam Probio/Herbal yang ASUH (Aman, Sehat, Utuh dan Halal) sebagai yang pertama dan satu-satunya di Provinsi Lampung.

Profil Kelompok Peternak Ayam (KPA) Berkat Usaha Bersama (BUB).Kelompok Peternak Ayam (KPA) Berkat Usaha Bersama (BUB) berdiri pada tanggal 22 Maret 2008 dengan nomor dan akta pendirian No. 21 Tanggal 05 Nyoman Dkk (Strategi Pemasaran Ayam Probio (Broiler) Pada Kelompok Peternak Ayam (Kpa) Berkat Usaha Bersama (Bub) Kota Metro) 
DOI: http://dx.doi.org/10.25181/jofsa.v2i1.759

Journal of Food System and Agribusiness Vol. 2 (1): 35-54

Agustus 2009 yang beralamat lengkap di Jl. Duku No. 12 RT/RW. 018/006 Yosomulyo $21 \mathrm{C}$ Metro Pusat, Kota Metro Provinsi Lampung.

Tabel 2. Struktur Organisasi KelompokPeternak Ayam (KPA) Berkat Usaha Bersama (BUB) Kota Metro

\begin{tabular}{|c|c|c|}
\hline No & Nama & Jabatan \\
\hline 1. & Yulius Wahyu Hidayanto & Ketua Kelompok \\
\hline 2. & Sri Wulandari & Sekretaris Kelompok \\
\hline 3. & Linda Sari & Bendahara Kelompok \\
\hline 4. & Agatha Widya Kinanti & Administrasi \\
\hline 5. & Andi Susanto & Petugas Penyuluh Lapangan Kelompok \\
\hline 6. & Masri'ah M Yassin & Petugas Penyuluh Lapangan Kelompok \\
\hline 7. & Syamijan & $\begin{array}{l}\text { Penyembelih bersertifikat Halal di RPA } \\
\text { Kelompok }\end{array}$ \\
\hline 8. & Anwaruddin & $\begin{array}{l}\text { Penyembelih bersertifikat Halal di RPA } \\
\text { Kelompok }\end{array}$ \\
\hline 9. & Kasirun. & Teknisi, Perawatan dan Peralatan. \\
\hline 10. & Yulianto & Quality Control di RPA Kelompok. \\
\hline 11. & Ricky Jusuf & Bagian Pasca Produksi di RPA Kelompok \\
\hline 12. & Muflihan Rossidin & $\begin{array}{l}\text { Quality Control di Rumah Pengolahan } \\
\text { Pakan }\end{array}$ \\
\hline 13. & Nunggarjito & $\begin{array}{l}\text { Penanggung jawab } \\
\text { Pakan. }\end{array}$ \\
\hline 14. & $\begin{array}{l}\text { Drh. Ruri Astuti } \\
\text { Wulandari }\end{array}$ & $\begin{array}{l}\text { Penanggung Jawab } \\
\text { Kelompok(Kesmavet) }\end{array}$ \\
\hline 15. & Drh. Vita Maharjanti & $\begin{array}{l}\text { Penanggung Jawab Teknis } \\
\text { Kelompok(Tehnis budidaya) }\end{array}$ \\
\hline
\end{tabular}

Berdasarkan Tabel 2 Kelompok Peternak Ayam (KPA) Berkat Usaha Bersama (BUB) Kota Metro memiliki jumlah anggota untuk peternak ayam yaitu 30 orang 22 pternak pria dan 8 peternak wanita dengan sebaran anggota didaerah Kota Metro berjumlah 11 orang peternak, Kabupaten Lampung Tengah 11 orang peternak dan Kabuoaten Lampung Timur 8 orang peternak. Jenis kegiatan yang dilakukan oleh kelompok yaitu (1) pengadaan dan pengolahan jamu/herbal untuk ayam probio yang material bahan diperoleh dari kebun herbal kelompok dan kebun herbal perseorangan. (2) Rumah Potong Ayam (RPA) kegiatan ini mampu Nyoman Dkk (Strategi Pemasaran Ayam Probio (Broiler) Pada Kelompok Peternak Ayam (Kpa) Berkat Usaha Bersama (Bub) Kota Metro) 
DOI: http://dx.doi.org/10.25181/jofsa.v2i1.759

Journal of Food System and Agribusiness Vol. 2 (1): 35-54

menyerap 35 orang tenaga kerja serta terciptanya lapangan dan tenaga kerja baru untuk memasarkan produk sampingan seperti ceker, kepala, hati, ampla dan usus ayam probio. (3) pengolahan pakan ayam dengan bahan baku pakan diperoleh dari petani jagung perorangan dan kelompok petani jagung binaan KPA BUB. (4) pengolahan produk ayam probio menjadi nugget ayam probio dan pengolahan keripik usus ayam probio dan (5) kegiatan yang dilakukan Kelompok Peternak Ayam (KPA) Berkat Usaha Bersama (BUB) adalah koperasi simpan pinjam.

\section{Analisis Strategi}

Analisis Faktor Internal dan Eksternal Menggunakan Matrik IFAS

dan EFAS. Berdasarkan identifikasi terhadap faktor-faktor Internal Faktor Analisysis Strategic (IFAS) dan Eksternal Faktor Analisysis Strategic (EFAS) diperoleh kekuatan dan kelemahan, peluang dan ancaman yang dimiliki oleh Kelompok Peternak Ayam (KPA) Berkat Usaha Bersama (BUB) Kota Metro. Faktor-faktor strategi internal dan eksternal diperoleh dari hasil wawancara dan pengisian kuesioner oleh konsumen, dan peternak Ayam Probio.Pembobotan dilakukan dengan menggunakan tabel perhitungan untuk mendapatkan bobot masing-masing variabel internal dan eksternal. Bobot yang digunakan merupakan hasil total pembobotan rat-rata dari petani. Pemberian peringkat (rating) diperoleh dari petani yang sama, sehingga diperoleh nilai dari faktor-faktor strategi internal dan eksternal. Dengan memasukan identifikasi kekuatan, kelemahan, peluang, dan ancaman.Kemudian diberi bobot dan peringkat maka diperoleh skor pembobotan.

Tabel 3. Matrik Internal Faktor Analisysis Strategic (IFAS)

\begin{tabular}{lccc}
\hline Faktor-faktor Strategi Internal & Bobot & Rating & $\begin{array}{c}\text { Skor } \\
\text { Pembobotan }\end{array}$ \\
\hline Kekuatan & & & \\
- Melakukan pengembangan produk ayam & 21,67 & 3,32 & 0,72 \\
$\quad$ probio & 11,67 & 3,32 & 0,39 \\
- Pelayanan terhadap konsumen yang baik & 23,33 & 3,32 & 0,77 \\
- Kualitas produk yang dihasilkan & 10 & 2,84 & 0,28 \\
- Promosi/periklanan & 16,67 & 3,32 & 0,55 \\
- Kekuatan bisnis dan manajemen & 16,67 & 2,52 & 0,42 \\
- Lokasi usaha & & & \\
\hline Total & $\mathbf{1 0 0}$ & & $\mathbf{3 , 1 3}$ \\
\hline
\end{tabular}

Nyoman Dkk (Strategi Pemasaran Ayam Probio (Broiler) Pada Kelompok Peternak Ayam (Kpa) Berkat Usaha Bersama (Bub) Kota Metro) 
DOI: http://dx.doi.org/10.25181/jofsa.v2i1.759

Journal of Food System and Agribusiness Vol. 2 (1): 35-54

\begin{tabular}{lccc}
\hline Kelemahan & & & \\
- Fasilitas pabrik seperti alat produksi & 16,67 & 2,92 & 0,49 \\
yang kurang memadai & 20 & 2,84 & 0,57 \\
- Saluran distribusi terbatas & 3,33 & 3,24 & 0,11 \\
- Proses produksi yang lama & 3,33 & 3,24 & 0,11 \\
- Persediaan modal & 3,33 & 3,32 & 0,11 \\
- Perbedaan harga ayam probio dengan & 53,33 & 2,04 & 1,09 \\
$\quad$ ayam konvesional & & & \\
- SDM & & & \\
\hline Total & $\mathbf{1 0 0}$ & & $\mathbf{2 , 4 8}$ \\
\hline
\end{tabular}

Berdasarkan Tabel 3 menunjukkan hasil perhitungan dari matrik IFAS bahwa kekuatan utama Kelompok Peternak Ayam (KPA) Berkat Usaha Bersama (BUB) Kota Metro adalah kualitas produk yang dihasilkan dengan skor 0,77, hal ini dikarenakan produk Ayam Probio yang dihasilkan memiliki kualitas yang lebih baik dibandingkan Ayam Konvensional dari segi kesehatan produk dan cita rasa yang dapat memberikan kepuasan tersendiri bagi konsumen dan membuat konsumen tersebut memiliki loyalitas yang sangat tinggi terhadap produk Ayam Probio (Ahyari, 1990 dalam Hermawan, 2011). Hal ini didukung dengan adanya sertifikat dari Departemen Kesehatan pemerintah Indonesia yang mengindikasikan bahwa produk Ayam Probio dari Kelompok Peternak Ayam (KPA) Berkat Usaha Bersama (BUB) ini aman untuk dikonsumsi karena memenuhi syarat kesehatan yang telah ditentukan oleh pemerintah.

Faktor strategi internal yang merupakan kelemahan utama yang dimiliki oleh Kelompok Peternak Ayam (KPA) Berkat Usaha Bersama (BUB) adalah kurangnya SDM dengan skor 1,09. Hal ini menunjukan bahwa kurangnya sumberdaya manusia yang berkaitan dengan ketenagakerjaan mengakibatkan proses produksi Ayam Probio kurang efisien dan siklus usaha yang kurang baik(Marihot, 2002).Hasil analisis matrik IFAS untuk kekuatan mendapat skor 3,13 dan kelemahan mendapatkan skor 2,48. Sehingga diperoleh total nilai pada posisi internal rata-rata yang dilihat dari bobot yaitu 5,61. Hal ini menunjukan bahwa skor kekuatan pada pemasaran Ayam Probio Kelompok Peternak Ayam (KPA) Berkat Usaha Bersama (BUB) Kota Metro sangat baik dengan total skor 3,13 dibandingkan skor kelemahan yaitu dengan total skor 2,48.

Berdasarkan penilaian skor yang telah disusun, total skor pemasaran Ayam Probio pada Kelompok Peternak Ayam (KPA) Berkat Usaha Bersama (BUB) Kota Metro sebesar 5,61 termasuk dalam kategori sangat baikyaitu diatas rata-rata dari rating yang telah ditetapkan.Kelemahan pemasaran Ayam Probio pada Kelompok Peternak Ayam (KPA) Berkat Usaha Bersama (BUB) Kota Metro Nyoman Dkk (Strategi Pemasaran Ayam Probio (Broiler) Pada Kelompok Peternak Ayam (Kpa) Berkat Usaha Bersama (Bub) Kota Metro) 
DOI: http://dx.doi.org/10.25181/jofsa.v2i1.759

Journal of Food System and Agribusiness Vol. 2 (1): 35-54

harus lebih diperhatikan agar nantinya bisa diperkecil.Dari hasil tersebut KPA BUB harus mengindikasikan bahwa lemahnya posisi internal perusahaan dalam mengatasi kelemahan yang ada dengan kekuatan yang dimilikinya.

Tabel 3. Matrik Eksternal Faktors Analisysis Strategic(EFAS)

\begin{tabular}{lccc}
\hline Faktor-faktor Strategi Eksternal & Bobot & Rating & Skor Pembobotan \\
\hline Peluang & & & \\
- Pertumbuhan pasar & 17,27 & 3,3 & 0,57 \\
- Siklus penjulaan & 15,45 & 3,3 & 0,51 \\
- Jumlah produksi & 9,09 & 3,08 & 0,28 \\
- Pemasaran langsung & 27,27 & 2,64 & 0,72 \\
- Pola perilaku konsumen yang & 22,73 & 3,3 & 0,75 \\
$\quad$ semakin berkembang & 8,18 & 2,94 & 0,24 \\
- Kebutuhan konsumsi masyarakat & & & \\
$\quad$ akan ayam probio & & & \\
\hline Total & $\mathbf{1 0 0}$ & & $\mathbf{3 . 0 7}$ \\
\hline Ancaman & & & 0.15 \\
- Ketersediaan bahan baku (DOC) & 5.14 & 2.94 & 0.12 \\
- Peraturan pemerintah & 4 & 3.02 & 0.23 \\
- Perubahan teknologi & 8.57 & 2.7 & 0.51 \\
- Penetapan harga & 25.14 & 2.04 & 0.68 \\
- Klaim produsen dalam & 29.14 & 2.34 & 0.63 \\
$\quad$ menawarkan produk yang sama & 28 & 2.26 & \\
- Pengetahuan masyarakat & & & $\mathbf{2 . 3 2}$ \\
$\quad$ mengenai perbandingan produk & & & \\
\hline Total & $\mathbf{1 0 0}$ & & \\
\hline
\end{tabular}

Berdasarkan tabel 3.menunjukkan hasil perhitungan dari matrik EFAS bahwa Peluang utama yang dimiliki oleh Kelompok Peternak Ayam (KPA) Berkat Usaha Bersama (BUB) Kota Metro adalah pola perilaku konsumen yang semakin berkembang dengan skor 0,75. Selama ini sebagian besar perilaku konsumen masih cenderung mengabaikan pola hidup sehat dan mementingkan kuantitas dari pada kualitas dari sebuah produk makanan, hal ini dibutuhkan pergeseran pola hidup yang lebih mementingkan kualitas kesehatan, baik kesehatan manusia maupun kesehatan lingkungan (Maporina, 2005 dalam Airine, 2010). Hal ini menandakan dengan kesadaran konsumen yang semakin berkembang akan pola hidup sehat yangmemiliki keuntungan tersendiri bagi Kelompok Peternak Ayam (KPA) Berkat Usaha Bersama (BUB) untuk menarik konsumen untuk membeli produk Ayam Probioyang akan meningkatkan penjualan.

Nyoman Dkk (Strategi Pemasaran Ayam Probio (Broiler) Pada Kelompok Peternak Ayam (Kpa) Berkat Usaha Bersama (Bub) Kota Metro) 
DOI: http://dx.doi.org/10.25181/jofsa.v2i1.759

Journal of Food System and Agribusiness Vol. 2 (1): 35-54

Faktor strategi eksternal yang merupakan ancaman utama dari Kelompok Peternak Ayam (KPA) Berkat Usaha Bersama (BUB)adalah klaim produsen dalam menawarkan produk yang sama dengan skor 0,68. Sebagai sebuah badan usaha yang memproduksi produk Ayam Probio satu-satunya di Provinsi Lampung, tentu banyak sekali produsen lain yang mengklaim bahwa produk ayam mereka merupakan ayam probio namun belum dipastikan ayam mereka bersertifikat Ayam Probio yang akan berdampak buruk bagi Kelompok Peternak Ayam (KPA) Berkat Usaha Bersama (BUB).

Hasil analisis matrik EFAS untuk peluang mendapatkan skor 3.07 dan ancaman mendapatkan skor 2,32. Sehingga diperoleh total nilai eksternal rata-rata yaitu sebesar 5,39. Hal ini menandakan bahwa skor peluang yang dimiliki Kelompok Peternak Ayam (KPA) Berkat Usaha Bersama (BUB) Kota Metro lebih besar dari pada ancamannya.Berdasarkan penilaian skor yang telah disusun, total skor pemasaran Ayam Probio padaPeternak Ayam (KPA) Berkat Usaha Bersama (BUB) Kota Metro sebesar 5,39 termasuk kategori pemasaran yang sangatbaik yaitu berada di atas rata-rata nilai dari rating yang telah ditetapkan. Dengan demikian, KPA BUB harus mengindikasikan bahwa perusahaan mampu merespon dengan baik faktor eksternal dengan memanfaatkan peluang yang ada untuk mengatasi ancaman.

Berdasarkan hasil yang diperoleh dari matrik IFAS dan matrik EFAS maka dapat diketahui posisi usaha Ayam Probio pada Kelompok Peternak Ayam (KPA) Berkat Usaha Bersama (BUB) Kota Metro saat ini. Oleh sebab itu pemetaan posisi usaha Ayam Probio pada Kelompok Peternak Ayam (KPA) Berkat Usaha Bersama (BUB) Kota Metro sangat penting dalam pemilihan strategi yang ditetapkan. Berdasarkan hasil analisis yang telah dilakukan, total nilai pada metrik IFAS untuk kekuatan dan kelemahan sebesar 5,61, yang artinya faktor internal berada di atas rata-rata. Sedangkan total nilai pada matrik EFAS untuk peluang dan ancaman yaitu sebesar 5,39 yang artinya faktor eksternal berada di atas rata-rata.

Analisis SWOT digunakan untuk mengidentifikasi berbagai faktor untuk merumuskan strategi. Berdasarkan data faktor-faktor internal dan eksternal didapatkan skor pembobotan sebagai berikut : faktor kekuatan $=3,13$, faktor kelemahan $=2,48$, faktor peluang $=3,07$ dan faktor ancaman 2,32.

Skor pembobotan selanjutnya diplotkan pada gambar analisis diagram SWOT yang terdiri dari 4 kuadran yaitu:

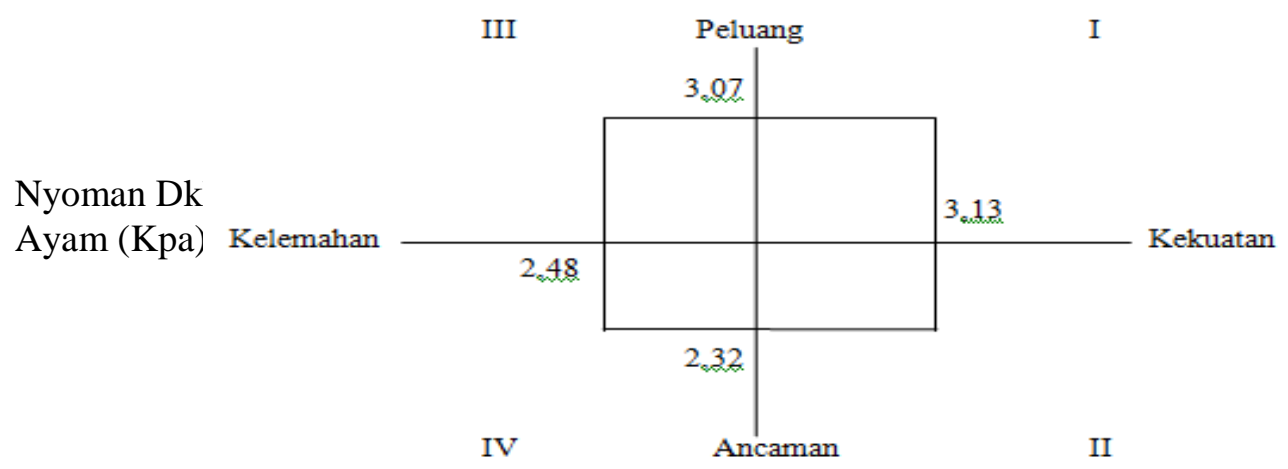


Gambar 2. Grafik Analisis SWOT Ayam Probio Pada Kelompok Peternak Ayam (KPA) Berkat Usaha Bersama (BUB) Kota Metro (01)

Dari perpotongan keempat garis faktor kekuatan, kelemahan, peluang dan ancaman, maka didapatkan koordinat $(0,65 ; 0,75)$ yaitu:

skor kekuatan - skor kelemahan ; skor peluang - skor ancaman

$$
2
$$

$\frac{3,13-2,48}{2} ; \frac{3,07-2,32}{2}$
0,$32 ; 0,37$

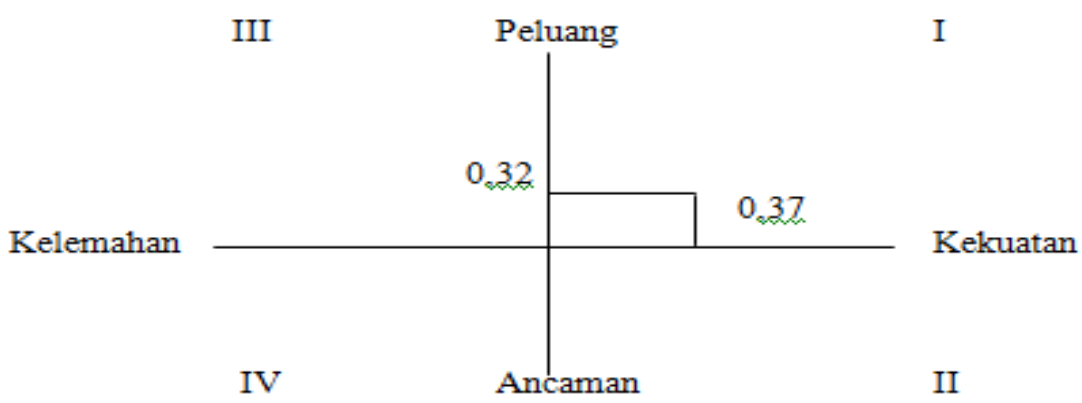

Gambar 3. Grafik Analisis SWOT usaha Ayam Probio Pada Kelompok Peternak Ayam (KPA) Berkat Usaha Bersama (BUB) Kota Metro (02)

Analisis SWOT yang dilakukan sebelumnya dapat digunakan sebagai dasar dalam penentuan strategi pemasaran Ayam Probio Pada Kelompok Peternak Ayam (KPA) Berkat Usaha Bersama (BUB) Kota Metrokedepan.Matrik SWOT ini dibangun berdasarkan hasil analisis faktor-faktor strategis internal maupun eksternal yang terdiri dari berbagai faktor kekuatan, kelemahan, peluang dan ancaman. Hasil analisis pada matrik SWOT diperoleh koordinat $(0,32 ; 0,37)$ yang mana koordinat ini masuk pada kuadran I, posisi ini menandakan bahwa usaha Nyoman Dkk (Strategi Pemasaran Ayam Probio (Broiler) Pada Kelompok Peternak Ayam (Kpa) Berkat Usaha Bersama (Bub) Kota Metro) 
DOI: http://dx.doi.org/10.25181/jofsa.v2i1.759

Journal of Food System and Agribusiness Vol. 2 (1): 35-54

Ayam Probio pada Kelompok Peternak Ayam (KPA) Berkat Usaha Bersama (BUB) Kota Metro yang kuat dan berpeluang. Rekomendasi strategi yang harus diberikan adalah Progresif yang artinya usaha Ayam Probio Pada Kelompok Peternak Ayam (KPA) Berkat Usaha Bersama (BUB) Kota Metro dalam kondisi prima dan mantap sehingga sangat memungkinkan untuk terus melakukan ekspansiusaha yang ditandai penciptaan pasar baru, memperbesar pertumbuhan pasar dan meraih kemajuan secara maksimal.

Perumusan Perioritas Strategi dengan Analisis SWOT. Perumusan perioritas dan keterkaitan antara strategi berdasarkan pembobotan rating hasil SWOT, maka dilakukan interaksi kombinasi strategi internal-eksternal, yang dapat dijelaskan sebagai berikut:

1. Interaksi kombinasi strategi SO merupakan strategi menggunakan kekuatan untuk memanfaatkan peluang, jika pemasaran Ayam Probio Pada Kelompok Peternak Ayam (KPA) Berkat Usaha Bersama (BUB) Kota Metro berada pada posisi ini maka mendukung pemasaran Ayam Probio kedepannya.

2. Interaksi kombinasi strategi WO merupakan strategi yang meminimalkan kelemahan untuk memanfaatkan peluang, jika usaha pemasaran Ayam Probio Pada Kelompok Peternak Ayam (KPA) Berkat Usaha Bersama (BUB) Kota Metro berada pada posisi ini maka masalah-masalah internal strategi pemasaran Ayam Probio dapat diusahakan dengan memanfaatkan peluang yang ada.

3. Interaksi kombinasi strategi ST merupakan strategi yang menggunakan kekuatan untuk mengatasi ancaman, jika usaha pemasaran Ayam Probio Pada Kelompok Peternak Ayam (KPA) Berkat Usaha Bersama (BUB) Kota Metro berada pada posisi ini strategi yang dilakukan adalah menggunakan kekuatan untuk mengatasi ancaman yang dihadapi oleh KPA BUB.

4. Interaksi kombinasi strategi WT merupakan strategi yang meminimalkan kelemahan untuk memanfaatkan ancaman. Apabila usaha pemasaran Ayam Probio Pada Kelompok Peternak Ayam (KPA) Berkat Usaha Bersama (BUB) Kota Metro sedang berada pada saat yang tidak menguntungkan. Hal ini karena usaha pemasaran Ayam Probio menghadapi kelemahan internal. Berdasarkan interaksi kombinasi tersebut, kemudian digabungkan dalam matrik seperti Tabel 4.

Tabel 4. Matrik Strategi Kombinasi Internal dan Eksternal

\begin{tabular}{|l|lcc|}
\hline \multirow{2}{*}{ EFAS } & IFAS & KEKUATAN $(S)$ & KELEMAHAN \\
& & $(W)$ \\
\hline
\end{tabular}

Nyoman Dkk (Strategi Pemasaran Ayam Probio (Broiler) Pada Kelompok Peternak Ayam (Kpa) Berkat Usaha Bersama (Bub) Kota Metro) 
DOI: http://dx.doi.org/10.25181/jofsa.v2i1.759

Journal of Food System and Agribusiness Vol. 2 (1): $35-54$

\begin{tabular}{|c|c|c|}
\hline PELUA & STRATEGI (SO) & STRATEGI ( \\
\hline ANCAM & STRATEGI (ST) & STRATEGI (WT) \\
\hline
\end{tabular}

Hasil penggabungan perhitungan pembobotan rating IFAS dan EFAS dapat dilihat pada Tabel 5 .

Tabel 5.Pembobotan rating IFAS dan EFAS

\begin{tabular}{|ccc|}
\hline & $\mathbf{O}=\mathbf{3 , 0 7}$ & $\mathbf{T}=\mathbf{2 , 3 2}$ \\
\hline $\mathbf{S}=\mathbf{3 , 1 3}$ & SO $=6,2$ & ST $=5,45$ \\
$\mathbf{W}=\mathbf{2 , 4 8}$ & WO $=5,55$ & WT $=4,8$ \\
\hline
\end{tabular}

Berdasarkan hasil pembobotan rating hasil kuesioner SWOT, maka dapat disusun prioritas strategi berdasarkan kombinasi strategi yang paling tinggi sampai dengan paling rendah, dapat dilihat pada Tabel 6

Tabel 6. Tingkat Prioritas Strategi SWOT

\begin{tabular}{|ccc|}
\hline Prioritas & Strategi & Bobot Nilai \\
\hline I & Strengh-Opportunity $(S O)$ & 6,2 \\
II & Weakness-Opportunity $(W O)$ & 5,55 \\
III & Strengh-Threat $(S T)$ & 5,45 \\
IV & Weakness-Threat $(W T)$ & 4,8 \\
\hline
\end{tabular}

Berdasarkan Tabel 6 menunjukkan hasil interaksi IFAS dan EFAS yang menghasikan alternatif strategi yang mendapatkan bobot tertinggi adalah StrenghOpportunity (SO) dengan skor 6,2, diterjemahkan sebagai strategi yang menggunakan kekuatan untuk memanfaatkan peluangseperti adanya pengembangan produk ayam probio menjadi sebuah peluang untuk meningkatkan jumlah produksi ayam probio sendiri (Rangkuti, 2004). Strategi untuk pemasaran Ayam Probio bobot kekuatan lebih besar dari pada kelemahan dan bobot peluang lebih besar dari pada ancaman dalam pemasaran Ayam Probio Pada Kelompok Peternak Ayam (KPA) Berkat Usaha Bersama (BUB) Kota Metro.

Tujuan dari tahap analisis terhadap faktor-faktor strategi (matrik SWOT) adalah untuk menghasilkan alternatif strategi yang layak.Berdasarkan analisis faktor internal dan eksternal perusahaan, maka dapat disusun beberapa alternatif strategi berdasarkan analisis matrik SWOT.Hasil dari analisis matrik SWOT pada

Nyoman Dkk (Strategi Pemasaran Ayam Probio (Broiler) Pada Kelompok Peternak Ayam (Kpa) Berkat Usaha Bersama (Bub) Kota Metro) 
DOI: http://dx.doi.org/10.25181/jofsa.v2i1.759

Journal of Food System and Agribusiness Vol. 2 (1): 35-54

pemasaran Ayam Probio Pada Kelompok Peternak Ayam (KPA) Berkat Usaha Bersama (BUB) Kota Metro dapat dilihat pada tabel 7.berikut ini.

Tabel 7. Matrik SWOT Pemasaran Ayam Probio Pada Kelompok Peternak Ayam (KPA) Berkat Usaha Bersama (BUB) Kota Metro

\begin{tabular}{|c|c|c|}
\hline (EFAS) & $\begin{array}{l}\text { Kekuatan (S) } \\
\text { 1. Melakukan pengembangan } \\
\text { produk ayam probio } \\
\text { 2. Pelayanan terhadap } \\
\text { konsumen yang baik } \\
\text { 3. Kualitas produk yang } \\
\text { dihasilkan } \\
\text { 4. Promosi/periklanan } \\
\text { 5. Kekuatan bisnis dan } \\
\text { manajemen } \\
\text { 6. Lokasi pabrik }\end{array}$ & 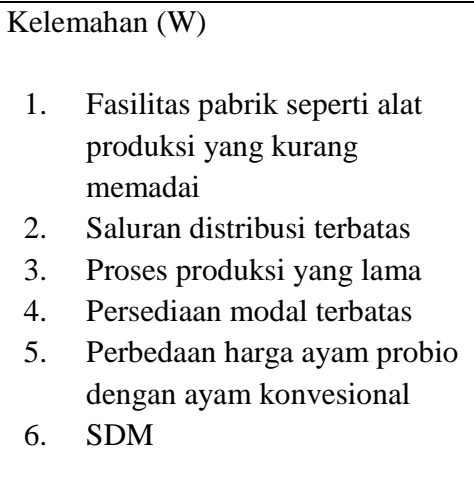 \\
\hline $\begin{array}{ll}\text { Peluang }(\mathrm{O}) \\
\text { 1. } \\
\text { 2. } & \text { Sertumbuhan pasar } \\
\text { 3. } & \text { Jumlah produksiaan } \\
\text { meningkat } \\
\text { 4. } \\
\text { 5emasaran langsung } \\
\text { Pola perilaku konsumen } \\
\text { yang semakin berkembang } \\
\text { Kebutuhan konsumsi } \\
\text { masyarakat akan ayam } \\
\text { probio }\end{array}$ & $\begin{array}{l}\text { Strategi S-O } \\
\text { 1. } \\
\text { pelakukan pengembangan } \\
\text { pelayanan terhadap } \\
\text { konsumen yang baik dengan } \\
\text { melihat pertumbuhan pasar } \\
\text { yang semakin berkembang } \\
\text { akan meningkatkan jumlah } \\
\text { produksi (S1,S2,O1,O3) } \\
\text { 2. } \\
\text { tengan pelayanan yang baik } \\
\text { kualitas produk yang baik } \\
\text { akan berpengaruh terhadap } \\
\text { siklus penjualan yang } \\
\text { semakin meningkat dengan } \\
\text { seiringnya pola perilaku } \\
\text { konsumen yang semakin } \\
\text { berkembang akan kebutuhan } \\
\text { masayrakat konsumsi ayam } \\
\text { probio(S2, S3,O2, O5, O6) } \\
\text { Kekuatan bisnis dan } \\
\text { manajemen yang baik dengan } \\
\text { memanfaatkan lokasi pabrik } \\
\text { yang strategis untuk } \\
\text { promosi/periklanan akan } \\
\text { meningkatkan jumlah } \\
\text { produksi sehingga kebutuhan } \\
\text { konsumi masyarakat akan } \\
\text { ayam probio akan terpenuhi } \\
\text { (S5 S6, S4, O3, O5) }\end{array}$ & $\begin{array}{l}\text { Strategi W-O } \\
\text { 1. Fasilitas pabrik seperti alat } \\
\text { produksi yang kurang memadai } \\
\text { dan saluran distribusi yang } \\
\text { terbatas serta persediaan modal } \\
\text { akan bisa teratasi ketika siklus } \\
\text { penjualan baik dan jumlah } \\
\text { produksi meningkat dan } \\
\text { adanya pemasaran langsung } \\
\text { dengan adanya kebutuhan } \\
\text { konsumsi masyarakat akan } \\
\text { ayam probio (W1, W2, W4, O2, } \\
\text { O3, O4, O6) } \\
\text { 2. Proses produksi yang lama yang } \\
\text { berdampak pada perbedaan } \\
\text { harga ayam probio dengan } \\
\text { ayam konvensional bisa teratasi } \\
\text { dengan keasadaran konsumen } \\
\text { yang terus berkembang akan } \\
\text { pola hidup sehat (W3, W5, O5) } \\
\text { Kekurangan SDM terutama } \\
\text { ketenagakerjaan dengan } \\
\text { seiringnya pertumbuhan pasar, } \\
\text { siklus penjualan yang baik dan } \\
\text { jumlah produksi yang } \\
\text { meningkat akan } \\
\text { meminimalisasikan kelemahan } \\
\text { KPA BUB (W6, O1, O2, O3) }\end{array}$ \\
\hline
\end{tabular}

Nyoman Dkk (Strategi Pemasaran Ayam Probio (Broiler) Pada Kelompok Peternak Ayam (Kpa) Berkat Usaha Bersama (Bub) Kota Metro) 
DOI: http://dx.doi.org/10.25181/jofsa.v2i1.759

Journal of Food System and Agribusiness Vol. 2 (1): $35-54$

\begin{tabular}{|c|c|c|}
\hline Ancaman (T) & Strategi S-T & Strategi W-T \\
\hline $\begin{array}{ll}\text { 1. } & \text { Ketersediaan bahan baku } \\
\text { (DOC) } \\
\text { 2. Peraturan pemerintah } \\
\text { 3. Perubahan teknologi } \\
\text { 4. Penetapan harga } \\
\text { 5. Claim produsen dalam } \\
\text { menawarkan produk yang } \\
\text { sama } \\
\text { 6. Pengetahuan masyarakat } \\
\text { mengenai perbandingan } \\
\text { produk ayam probio }\end{array}$ & $\begin{array}{l}\text { 1. Melakukan pengembangan } \\
\text { produk ayam probio serta } \\
\text { kualitas produk yang } \\
\text { dihasilkan dengan melihat } \\
\text { ketersediaan bahan baku } \\
\text { (DOC) yang terbatas, adanya } \\
\text { penetapan harga, claim } \\
\text { produsen dalam menawarkan } \\
\text { produk yang sama (S1, S3, } \\
\text { T1, T4, T5) } \\
\text { 2. Pelayanan terhadap } \\
\text { konsumen yang baik dan } \\
\text { penjualan promosi/periklanan } \\
\text { berpengaruh pada peraturan } \\
\text { pemerintah serta pengetahuan } \\
\text { masyarakat mengenai } \\
\text { perbandingan produk ayam } \\
\text { probio dengan ayam } \\
\text { konvensional (S2, S4, T2, } \\
\text { T6) } \\
\text { Kualitas produk yang } \\
\text { dihasilkan tetap baik, adanya } \\
\text { kekuatan bisnis dan } \\
\text { manajemen yang baik juga } \\
\text { serta lokasi pabrik yang } \\
\text { cukup strategis meskipun } \\
\text { terdapat perubahan teknologi } \\
\text { tidak akan mempengaruhi } \\
\text { usaha KPA BUB (S3, S5, S6, } \\
\text { T3) }\end{array}$ & $\begin{array}{l}\text { 1. Menambah saluran distribusi } \\
\text { untuk lebih memperkenalkan } \\
\text { produk yang dihasilkan dan } \\
\text { perbedaan harga ayam probio } \\
\text { kepada masyakat, agar } \\
\text { masyarakat mengetahui } \\
\text { mengenai perbandingan ayam } \\
\text { probio dengan ayam } \\
\text { konvensional (W2, W5, T6) } \\
\text { 2. Membangun dan } \\
\text { mengembangkan usaha } \\
\text { patungan (Joint Venture) } \\
\text { dengan pihak yang } \\
\text { menyediakan modal dan bahan } \\
\text { baku untuk meningkatkan } \\
\text { kapasitas produksi, memenuhi } \\
\text { kebutuhan modal yang masih } \\
\text { minim, terutama untuk } \\
\text { penambahan sarana dan } \\
\text { prasarana produksiserta riset } \\
\text { dan pengembangan produk } \\
\text { serta perubahan tektologi (W4, } \\
\text { T1, T3, W1, ) }\end{array}$ \\
\hline
\end{tabular}

Berdasarkan Tabel 7 menunjukkan bahwa Matrik SWOT Pemasaran Ayam Probio Pada Kelompok Peternak Ayam (KPA) Berkat Usaha Bersama (BUB) Kota Metro dapat dijabarkan sebagai berikut :

\section{Strategi S-O (Strenghts-Opportunities)}

Strategi ini adalah untuk memanfaatkan seluruh kekuatan untuk merebut dan memanfaatkan peluang sebesar-besarnya. Strategi yang dapat digunakan yaitu pertama, Melakukan pengembangan produk ayam probio dan pelayanan terhadap konsumen yang baik dengan melihat pertumbuhan pasar yang semakin berkembang akan meningkatkan jumlah produksi ayam probio. Kedua, Dengan pelayanan yang baik terhadap konsumen serta kualitas produk yang baik akan berpengaruh terhadap siklus penjualan yang semakin meningkat dengan seiringnya pola perilaku konsumen yang semakin berkembang akan kebutuhan masayrakat konsumsi ayam probio. Ketiga,Kekuatan bisnis dan manajemen yang baik dengan memanfaatkan lokasi pabrik yang strategis untuk promosi/periklanan

Nyoman Dkk (Strategi Pemasaran Ayam Probio (Broiler) Pada Kelompok Peternak Ayam (Kpa) Berkat Usaha Bersama (Bub) Kota Metro) 
DOI: http://dx.doi.org/10.25181/jofsa.v2i1.759

Journal of Food System and Agribusiness Vol. 2 (1): 35-54

akan meningkatkan jumlah produksisehingga kebutuhan masyarakat akan ayam probio bisa terpenuhi.

\section{Strategi S-T (Strenghts-Treathts)}

Strategi ini adalah untuk menggunakan kekuatan yang dimiliki perusahaan untuk mengatasi ancaman. Strategi yang dapat digunakan yaitu pertama, dengan Melakukan pengembangan produk ayam probio serta kualitas produk yang dihasilkan tetap baik dengan melihat ketersediaan bahan baku (DOC) yang terbatas, adanya penetapan harga, claim produsen dalam menawarkan produk yang sama. Kedua, pelayanan terhadap konsumen danpromosi/periklananyang baik berpengaruh pada peraturan pemerintah serta pengetahuan masyarakat mengenai perbandingan produk ayam probio dengan ayam konvensional. Ketiga, Kualitas produk yang dihasilkan tetap baik, adanya kekuatan bisnis dan manajemen yang baik juga serta lokasi pabrik yang strategis meskipun terdapat perubahan teknologi tidak akan mempengaruhi usaha KPA BUB.

\section{Strategi W-O (Weaknesses-Opportunities)}

Strategi ini diterapkan berdasakan pemanfaatan peluang yang ada dengan cara meminimalkan kelemahan yang ada. Strategi yang dapat digunakan yaitu yang pertama, Fasilitas pabrik seperti alat produksi yang kurang memadai dan saluran distribusi yang terbatas serta persediaan modal akan bisa teratasi ketika siklus penjualan baik dan jumlah produksi meningkat danadanya pemasaran langsung dengan adanya kebutuhan konsumsi masyarakat akan ayam probio. Kedua, Proses produksi yang lama yang berdampak pada perbedaan harga ayam probio dengan ayam konvensional bisa teratasi dengan keasadaran konsumen yang terus berkembang akan pola hidup sehat. Ketiga Kekurangan SDM terutama ketenagakerjaan dengan seiringnya pertumbuhan pasar, siklus penjualan yang baik dan jumlah produksi yang meningkat akan meminimalisasikan kelemahan.

\section{Strategi W-T (Weaknesses- Treathts)}

Strategi ini didasarkan pada kegiatan perusahaan yang bersifat defensif dan berusaha meminimalkan kelemahan yang ada serta menghindari ancaman.Strategi yang dapat dilakukan yaitu pertama, menambah saluran distribusi yang lebih luas untuk lebih memperkenalkan produk yang dihasilkan dan perbedaan harga ayam probio kepada masyakat, agar masyarakat mengetahui mengenai perbandingan ayam probio dengan ayam konvensional.Kedua, membangun dan mengembangkan usaha patungan (Joint Venture) dengan pihak yang menyediakan modal dan bahan baku untuk meningkatkan kapasitas produksi, memenuhi kebutuhan modal yang masih minim, terutama untuk penambahan sarana dan prasarana produksi serta riset dan pengembangan produkserta perubahan tektologi.

Nyoman Dkk (Strategi Pemasaran Ayam Probio (Broiler) Pada Kelompok Peternak Ayam (Kpa) Berkat Usaha Bersama (Bub) Kota Metro) 
DOI: http://dx.doi.org/10.25181/jofsa.v2i1.759

Journal of Food System and Agribusiness Vol. 2 (1): 35-54

Berdasarkan hasil pembobotan nilai tertinggi adalah strategi StrenghOpporturnities ( $\mathrm{SO}$ ) terletak pada kuadran I. Pada kuadran ini menandakan bahwa usaha Ayam Probio pada Kelompok Peternak Ayam (KPA) Berkat Usaha Bersama (BUB) Kota Metro yang kuat dan berpeluang. Tingginya strategi nilai prioritas SO bukan berarti strategi lain yang memiliki nilai lebih rendah tidak bermanfaat dan tidak perlu diterapkan. Akan tetapi, apabila ingin mendapatkan hasil yang maksimal strategi SO, WO, dan WT harus ikut dilaksanakan.

\section{KESIMPULAN DAN SARAN}

Kesimpulan. Berdasarkan hasil analisis pada matrik SWOT diperolehkoordinat $(0,32 ; 0,37)$ yaitu strategi Strengh-Opporturnities (SO) yang mana koordinat ini masuk pada kuadran I. Rekomendasi srategi yang dapat dilaksanakan Kelompok Peternak Ayam (KPA) Berkat Usaha Bersama (BUB) Kota Metro adalah :

1. Melakukan pengembangan produk ayam probio dan pelayanan terhadap konsumen yang baik dengan melihat pertumbuhan pasar yang semakin berkembang akan meningkatkan jumlah produksi ayam probio (S1, S2, O1, O3).

2. Dengan pelayanan yang baik terhadap konsumen serta kualitas produk yang baik akan berpengaruh terhadap siklus penjualan yang semakin meningkat dengan seiringnya pola perilaku konsumen yang semakin berkembang akan kebutuhan masayrakat konsumsi ayam probio (S2, S3, O2, O5, O6).

3. Kekuatan bisnis dan manajemen yang baik dengan memanfaatkan lokasi pabrik yang strategis untuk promosi/periklanan akan meningkatkan jumlah produksi sehingga kebutuhan masyarakat akan ayam probio bisa terpenuhi (S5, S6, S4, O3, O5).

Saran. Bagi Kelompok Peternak Ayam (KPA) Berkat Usaha Bersama (BUB) Kota Metrosebaiknya harus komprehensif mengatasi masalah tenaga kerja dan Kelompok Peternak Ayam (KPA) Berkat Usaha Bersama (BUB) harus membuat kegiatan program pengembangan keterampilan dan keahlian untuk para pegawai baru maupun lama dan para peternak agar mempunyai sumberdaya manusia (SDM) yang berkualitas agar usaha yang dijalankan lebih berkembang serta mampu bersaing dengan perusahaan-perusahaan yang menghasilkan produk yang sama.

\section{UCAPAN TERIMAKASIH}

Puji dan syukur kami panjatkan kehadirat Tuhan Yang Esa, karena berkat rahmad dan karunia Nya semata sehingga kami mampu menyelesaikan penelitian Nyoman Dkk (Strategi Pemasaran Ayam Probio (Broiler) Pada Kelompok Peternak Ayam (Kpa) Berkat Usaha Bersama (Bub) Kota Metro) 
DOI: http://dx.doi.org/10.25181/jofsa.v2i1.759

Journal of Food System and Agribusiness Vol. 2 (1): 35-54

dengan judul "Strategi Pemasaran Ayam Probio (broiler) Pada Kelompok Peternak Ayam (KPA) Berkat Usaha Bersama (BUB) Kota Metro" dapat terlaksana dengan baik. Untuk itu, pada kesempatan ini penulis mengucapkan banyak terima kasih kepada Ibu Ir. Rakhmiati, M.T.A, yang telah memberikan bantuan moril maupun materil selama penelitian dan seluruh civitas STIPER Dharma Wacana Metro atas semua ilmu yang bermanfaat yang telah diberikan kepada kami dalam penyelesaikan penelitian ini.

\section{DAFTAR PUSTAKA}

Airine, T. Analisis Perilaku Konsumen Sayuran Organik (Studi Kasus: Giant Botani Square, Kota Bogor, Jawa Barat).

Arifin, B. (2004). Analisis ekonomi pertanian Indonesia. Penerbit Buku Kompas.

Badan Penelitian Dan Pengembangan Pertanian. (2007). Prospek Dan Arah Pengembangan Agribisnis Ungggas. Edisi Kedua Departemen Peretanian. Jakarta.

Badan Pusat Statistik Lampung 2012-2016. Populasi Ternak Menurut Kabupaten/Kota Dan Jenis Ternak di Provinsi Lampung

Direktorat Jendral Pengolahan dan Pemasaran Hasil Pertanian. (2014). Berita Ayam Probio untuk Hidup Lebih Sehat.

Hermawan, B. (2011). Pengaruh Kualitas Produk Terhadap Kepuasan, Reputasi Merek dan Loyalitas Konsumen Jamu Tolak Angin PT. Sido Muncul. Jurnal Manajemen Teori dan Terapan| Journal of Theory and Applied Management, 4(2).

Jayanata, C. E., \& Harianto, B. (2011). 28 Hari Panen Ayam Broiler. AgroMedia.

Rangkuti, D. F. (2004). Manajemen Strategi Edisi Kesepuluh. Jakarta : Salemba Empat.

(2010). Manajemen Strategis Edisi Keduabelas. Jakarta : Salemba

Empat.

. (2010). Analis SWOT Teknik Membedah Kasus Bisnis. Jakarta :

Nyoman Dkk (Strategi Pemasaran Ayam Probio (Broiler) Pada Kelompok Peternak Ayam (Kpa) Berkat Usaha Bersama (Bub) Kota Metro) 
DOI: http://dx.doi.org/10.25181/jofsa.v2i1.759

Journal of Food System and Agribusiness Vol. 2 (1): 35-54

PT Gramedia Pustaka Utama.

Sugiyono. (2009). Metode Penelitian Bisnis (Pendekatan Kuantitatif, Kualitatif, dan R\&D). Bandung : Alfabeta.

Zulkarnain, Z. (2017). Analisis Strategi Pengembangan Pemasaran dan Nilai Tambah Tiwul Instan. Journal of Food System and Agribusiness (JoFSA), 1(1), 1-11. Retrieved from http://jurnal.polinelasrv.id/index.php/JOFSA/article/view/79

Nyoman Dkk (Strategi Pemasaran Ayam Probio (Broiler) Pada Kelompok Peternak Ayam (Kpa) Berkat Usaha Bersama (Bub) Kota Metro) 